\title{
Proposta de um Modelo de Ensino para Aplicabilidade do PBL utilizando Recursos AVAs para Alunos do Ensino Médio
}

\author{
Marília Nayara Clemente de Almeida Lima ${ }^{1}$, Wylliams Barbosa Santos ${ }^{1,2}$ \\ ${ }^{1}$ Instituto de Informática - Universidade de Pernambuco (UPE) \\ Caruaru - PE - Brasil \\ ${ }^{2}$ Centro de Informática - Universidade Federal de Pernambuco (UFPE) \\ Recife - PE - Brasil \\ marilianayara@gmail.com, wbs@upe.br
}

\begin{abstract}
Objective: To propose a teaching model that uses the PBL teaching methodology and AVA resources for high school students. Methods:This is a basic qualitative research. Results:Obtained the proposal of the teaching model, as well as its description and use by both the teacher and the students. Conclusion: Satisfactory results are expected, since the resources used for the proposal have obtained good results in other studies; So that students can improve their communication and leadership.
\end{abstract}

Resumo. Objetivo:Propor um modelo de ensino que utilize a metodologia de ensino PBL e recursos AVAs para alunos do Ensino médio. Métodos: Trata-se de uma pesquisa qualitativa básica. Resultados: Obteve a proposta do modelo de ensino, assim como sua descrição e utilização tanto pelo professor quanto pelos discentes. Conclusão: Espera-se resultados satisfatórios, pois outros estudos apresentaram bons resultados com a adoção de recursos semelhantes; dessa forma os discentes poderão melhorar sua comunicação e espírito de liderança.

\section{Introdução}

O PBL (Problem-Basead Learnig) é considerado uma metodologia de ensino colaborativa e contextualizada, em que através de problemas, exercícios ou projetos propostos pelo professor, e vinculado a aspectos reais, estimulam a aprendizagem dos discentes [Angelo and Bertoni 2012]. A metodologia teve seus primeiros vestígios na área médica, na escola McMaster, no Canadá; e depois em outras escolas como Harvard e Havaí, nos Estados Unidos a adoram [Pires et al. 2010]. A base do PBL é o problema, visto que todo processo na sala de aula estar relacionado ao mesmo, já que antes de qualquer exposição teórica do conteúdo o professor apresenta o problema ao aluno, para que este tente solucionar, sendo assim os discentes tem que ir em busca de seu conhecimento [Rocha et al. 2016]. No intuito de contribuir com uma melhor participação do aluno no processo de aprendizagem existem os Ambientes Virtuais de aprendizagem (AVAs), esses ambientes têm como características a utilização de recursos digitais (plataformas), com o objetivo de tornar uma dinâmica mais flexível para, por exemplo, a proposta e resolução de exercícios.

Seguindo esse pressuposto, o artigo tem por objetivo propor um modelo pedagógico para suporte e utilização da metodologia de ensino do PBL, tendo como auxílio 
VI Congresso Brasileiro de Informática na Educação (CBIE 2017)

Anais do XXIII Workshop de Informática na Escola (WIE 2017)

os AVAs, no contexto do ensino médio, visto que a metodologia de ensino em questão, segundo [de Oliveira et al. 2010] proporciona melhor espírito de liderança e comunicação para os discentes; como também os AVAs contribuem para proporcionar maior flexibilidade para a disponibilidade de conteúdo para os alunos. A pesquisa esta focada para os alunos do ensino médio, pois é comum que as aulas sejam ministradas seguindo o modelo tradicional de ensino.

Na educação a distância são adotados processos que vão além da distância física, pois também são usadas nas modalidades de ensino presencial de forma eficaz, já que os recursos dos AVAs além de diminuir a distância entre o aluno, funcionam como uma auxiliadores no processo de aprendizado [Franco et al. 2003]. Quando se fala em opção midiática que é utilizada para mediar o procedimento de transmissão de conhecimento e aprendizagem a distância, se fala em AVAs [Moraes et al. 2004]. Nesse contexto, o computador é visto como um meio para o desenvolvimento social, cognitivo e afetivo do sujeito.

\section{Métodos}

Quanto aos fins, a presente pesquisa é de natureza descritiva, que segundo [Gil 2002], "são aquelas pesquisas que têm como preocupação central identificar os fatores que determinam ou que contribuem para a ocorrência dos fenômenos". Quanto aos Meios, a pesquisa é de natureza bibliográfica, que, de acordo [Gil 2002], "A pesquisa bibliográfica é desenvolvida com base em material já elaborado, constituído principalmente de livros e artigos científicos". Quanto a Forma de Abordagem, a pesquisa tem característica qualitativa, que segundo [Gil 2002] "uma análise qualitativa depende de muitos fatores, tais como a natureza dos dados coletados, a extensão da amostra, os instrumentos de pesquisa e os pressupostos teóricos que nortearam a investigação."

\section{Resultados}

O modelo pedagógico proposto nesse artigo, está ilustrado na Figura 1. O modelo busca aprimorar o modelo de [Lima et al. 2016]. No modelo, o instrutor, tem a função do professor, na qual irá repassar o conteúdo teórico e os problemas aos discentes, ele ainda é responsável por elaborar os problemas, como fazer a avaliação final do que foi pedido na sala de aula [Lima et al. 2016]. As equipes são formadas pelos alunos que cursam a disciplina, e assim como no modelo tradicional de ensino, os discentes devem buscar resolver o que foi proposto pelo instrutor. Sendo que no PBL, os problemas são resolvidos em equipes, nesse pressuposto, depois que as equipes estão formadas, cada uma irá resolver o que foi pedido. Para isso, faz-se necessário que a equipe passe por etapas para resolução do problema, que vão desde a Chuva de ideias, Sistematização, formulação de questões, metas e avaliação do processo.

$\mathrm{Na}$ etapa da chuva de ideias, os alunos irão expor, entre a equipe, como pretende resolver o que foi pedido, para isso devem elaborar ideias, hipóteses; também é nessa etapa onde é feito um estudo sobre o tema que o problema foi proposto. Já a sistematização, é feito a escolha do que é mais conveniente para resolver o mesmo, através de critérios que a equipe propôs e concordaram. Na etapa da formulação de questões, a equipe irá elabora perguntas com o objetivo de responder o problema. Já a etapa das metas refere-se a elaboração de objetivos de como seguir para responder o problema, mediante as questões elaboradas na etapa anterior. A etapa de avaliação do processo, como 
VI Congresso Brasileiro de Informática na Educação (CBIE 2017)

Anais do XXIII Workshop de Informática na Escola (WIE 2017)

o próprio nome sugere, é feito as considerações do que foi desenvolvido para a solução do problema, ressaltado também os pontos positivos e negativos, visto que esta avaliação é feita pela própria equipe.

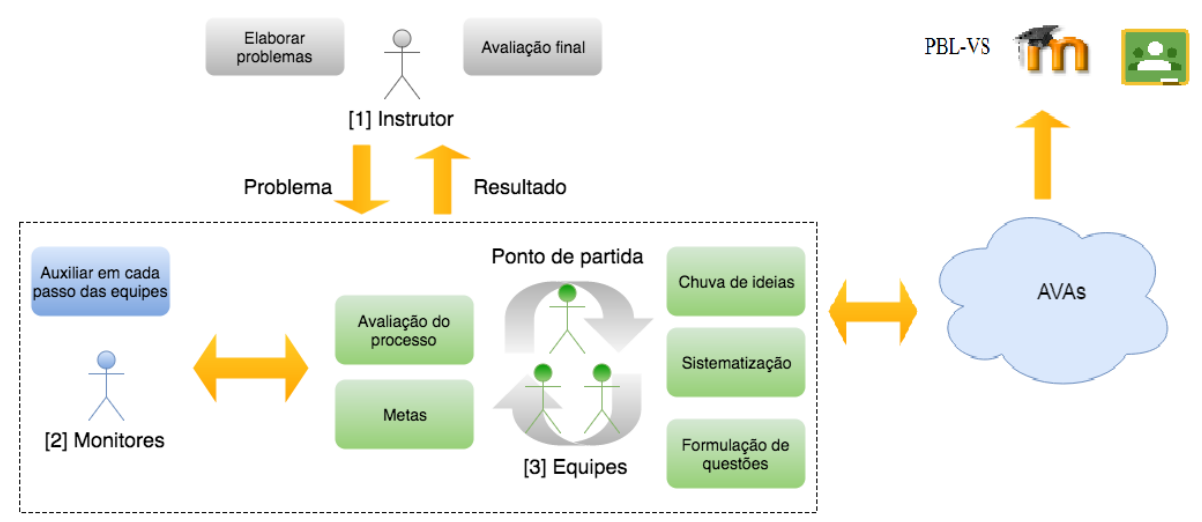

Figura 1. Proposta do Modelo de ensino (Adaptado de [Lima et al. 2016])

É essencial que cada membro da equipe busque a solução do problema, pois vai contribuir para seu desenvolvimento profissional e pessoal. As equipes devem ser formadas por pessoas com diferentes traços de personalidade, para que o trabalho em equipe se desenvolva com maior fluidez. Para isso o professor deve formar as equipes, mediante critérios socioafetivos, visto que segundo [Almeida et al. 2016] a formação de grupos na sala de aula, é formada por critérios de afinidade, proximidade e amizade com os demais membros do grupo, podendo o trabalho não ser desenvolvido como esperado.

Em virtude disso, [Almeida et al. 2016] propõe que os grupos sejam formados mediante critérios socioafetivos, para tal, o mesmo estabeleceu critérios para a formação do grupo. Esses critérios são de pessoas que apresentam um perfil de líder, ativo, social, amorfo entre outros. No estudo o autor demonstrou, por exemplo, que pessoas que tem o perfil de líder se estão no mesmo grupo podem vir a ter conflitos, assim como pessoas que tem o perfil amorfo, e não tem nenhum outra pessoa pro ativa, o trabalho pode não ter a mesma fluidez. Por isso na formação do grupo é preciso que o professor interfira, e forme grupos mistos, que contenham pessoas de perfis de líder, amorfo, ativo, social no mesmo grupo. Se não existir pessoas com perfis de líder, por exemplo, é preciso que o grupo seja formado pelo discente que mais se aproxime desse perfil, como o ativo. Para que o professor tenha conhecimento do perfil de cada discente o mesmo pode realizar o questionário de Roger Verdier, assim como [Almeida et al. 2016] fez em seu estudo. O questionário conta com quinze questões, as mesma ainda podem ser disponibilizadas para os discentes através dos AVAs ou respondido presencialmente.

Outro elemento fundamental no modelo é o monitor, que representa os tutores na metodologia PBL, é necessário que seja pessoas especialista na disciplina. O monitor tem o papel de auxiliar as equipes em todas as etapas que elas passam para resolver os problemas que foram propostos pelo instrutor. O monitor deve esta auxiliando cada equipe de forma a sanar as dúvidas que essas venham a ter, assim como se preciso fazer uma breve explanação teórica a respeito do conteúdo. O mesmo ainda tem o papel de guiar a equipe pelo caminho correto da resolução do problema. Logo o monitor e as equipes tem contato direto e constante. Em virtude desse fato, e buscando tornar a dinâmica entre 
o monitor e os discentes mais eficiente, é proposto o auxilio de AVAs para que mesmo em casa o discente possa esclarecer dúvidas com o monitor. Como também o professor irá disponibilizar os temas dos conteúdos que irão ser ministrado na sala de aula, além de disponibilizar os problemas (exercícios). Dessa forma os AVAs vão ser um complemento do que os alunos irão ter em suas aulas presenciais, pois deverão ser disponibilizados exercícios que ainda não teriam sido repassados para os discentes, porém é preciso que os problemas proposto na sala de aula também estejam presentes.

Os AVAs pode ser escolhido a critério do professor e monitor, uns bem conhecido são o Google Classroom e Moodle. O Moodle, por exemplo, foi utilizado no estudo de [Mezzari et al. 2011], o qual demonstrou, que no curso que foi feito o estudo, não causa perdas a qualidade do ensino oferecido e sim contribui para a formação profissional dos discentes. Dessa forma os AVAs tem o papel de estabelecer um elo mais efetivo entre os discentes e monitores, pois mesmo não tendo contato presencial as dúvidas poderão ser sanadas. Com isso, os discentes terão maior flexibilidade, e terão a oportunidade de ter os conteúdos disponíveis, mesmo quando venha a faltar a aula. Tanto o professor quanto monitores devem escolher, a medida de cada problema, alunos para apresenta o mesmo, pois assim irá trabalhar a comunicação e a oralidade do discente. $\mathrm{O}$ momento em que existe a interação entre os discentes e os monitores é chamada de sessão tutorial. No modelo a sessão tutorial, terá um enfoque maior, pois além do contato presencial que os discentes irão ter com os monitores, com o auxilio do AVAs, esse contato será muito mais eficiente, já que os alunos terão uma maior disponibilidade de conteúdo, e um contato presencial e a distancia com os monitores.

Seguindo esse pressuposto, o esquema metodológico do modelo proposto, está segue três etapas. A primeira é referente ao professor apresentar o problema aos discentes, e que pode ser acompanha de uma breve explanação teórica do conteúdo, caso o tema seja complexo e os alunos venham a ter muitas dificuldades para começar a resolver o problema. Em seguida, a segunda etapa, consiste na sessão tutorial, onde os alunos terão o contato com os monitores tanto presencial quanto a distancia, permitido através dos recursos dos AVAs. Na terceira etapa, o professor irá realizar a explanação teórica do conteúdo, assim como fazer a avaliação final do problema, ressaltando os pontos positivos e negativos da resolução do exercício. Para o modelo que está sendo proposto traga bons resultados nas disciplinas que for ser aplicado, é necessário o comprometimento por parte de todos os elementos envolvidos. Para que assim se consiga desenvolver a metodologia PBL de forma coerente, e que os AVAs venham a contribuir para o processo de aprendizado dos alunos, assim como dos instrutores e monitores.

\section{Conclusão}

O artigo faz uma proposta de uma modelo pedagógico que tem como base a metodologia PBL, assim como o auxilio dos benefícios que os AVAs proporcionam aos estudantes e docentes. O modelo pode acarretar muitos benefícios, pois outras referencias mostram resultados positivos da aplicação da metodologia PBL, como também a utilização dos AVAs. Desse modo o modelo busca proporcionar ao discente maior espírito de liderança, uma melhor comunicação e trabalho em equipe de forma a trazer bons resultados, princípios esses que são característica da metodologia PBL. Outras importantes características são a flexibilidade e disponibilidade de conteúdo, que é proporcionado pelos AVAs. Nesse pressuposto, o artigo teve o intuito de proporcionar aos discentes 
VI Congresso Brasileiro de Informática na Educação (CBIE 2017)

Anais do XXIII Workshop de Informática na Escola (WIE 2017)

uma participação ativa no seu processo de ensino e aprendizagem, além de que os alunos poderão vivenciar experiências, que antes só era possível no mercado de trabalho. Os professores também serão beneficiados, pois irão sempre estar em um contato mais flexível com os alunos.Desse modo, o modelo pedagógico proposto poderá acarretar resultados satisfatórios, visto que outros trabalhos relacionado, como o de [Rocha et al. 2016], ao usar essa temática, trouxe resultados positivos. Logo, o presente trabalho, refere-se a um estudo empírico do modelo proposto.

Por fim, a aplicação desse modelo poderia ser realizado em alguma disciplina, inicialmente, para demonstrar se realmente o modelo será eficiente. Dessa forma, poderá ser aperfeiçoado ou confirmar melhores resultados, possibilitando sua aplicabilidade em mais disciplinas. Como trabalhos futuros pretende-se mostrar a aplicação desse modelo em alguma escola, que ministre aulas para alunos do ensino médio.

\section{Referências}

Almeida, G. K. F. C., Almeida, W. R. M., Júnior, A. C. P. R.and Lima, T. D. V., and Magalhães, Y. C. (2016). Development of a clustering algorithm tool to give support for working group training environments teaching - learning considering socio-affective factor. CONTECSI - International Conference on Information Systems and Technology Management, pages 2386-2414.

Angelo, M. F. and Bertoni, F. C. (2012). Análise da aplicação do método pbl no processo de ensino e aprendizagem em um curso de engenharia de computação. Revista de Ensino de Engenharia, 30(2):35-42.

de Oliveira, W. L., Dias, A. M., Apolinário Jr, A. L., Duarte, A. A., and de Oliveira, T. (2010). Aplicando pbl no ensino de arquitetura de computadores.

Franco, M. A., Cordeiro, L. M., CASTILLO, R. A. d., et al. (2003). O ambiente virtual de aprendizagem e sua incorporação na unicamp. Educação e Pesquisa, 29(2):341-353.

Gil, A. C. (2002). Como elaborar projetos de pesquisa. São Paulo, 5:61.

Lima, M. N. C. d. A., Rocha, E., Santos, W., Xavier, E., Moutinho, M., Fonseca, J., et al. (2016). Caruaru arretado: Utilização de problem-based learning (pbl) em um curso de desenvolvimento de jogos para alunos do ensino médio. In Anais dos Workshops do Congresso Brasileiro de Informática na Educação, volume 5, page 354.

Mezzari, A., Iser, I. C., Wiebbelling, A. M. P., and Tarouco, L. M. R. (2011). O uso do problem based learning (pbl) como reforço ao ensino presencial utilizando o ambiente de aprendizagem moodle. Revista brasileira de educação médica= Brazilian journal of medical education. Vol. 35, n. 1 (2011), p. 114-121.

Moraes, M. d. et al. (2004). A monitoria como serviço de apoio ao aluno na educação a distância.

Pires, M. G., Bertoni, F. C., and Angelo, M. F. (2010). Aprendizagem baseada em problemas aplicada ao ensino de compiladores em engenharia de computaçao. In PBL 2010 Congresso Internacional, pages 8-12.

Rocha, d. S., Lima, M. N. C. d. A., and Santos, W. B. (2016). Problem based learning in the project management classroom. CONTECSI - International Conference on Information Systems and Technology Management, pages 2740-2751. 